\title{
Influence of keratin on the growth of some keratinophilic fungi
}

\author{
Namita Kumari ${ }^{1}$ Arvind Kumar ${ }^{2}$ \\ ${ }^{I}$ (Department of Botany, Magadh Mahila College ,Patna University, Patna, India). \\ ${ }^{2}$ (Department of Chemistry, College of Commerce,Patna Magadh University, India).
}

\begin{abstract}
During our investigation, some fungal species were isolated which are keratinophilic in nature.They frequently occurred on hair, feather, nail, hoof, horn and skin Some of them are potentially pathogenic, causing so many skin diseases in human beings and animals. The considerable growth of these isolates on keratin like polymer is not at all possible without the hydrolysis to simpler fractions. The present finding corroborates the keratin digesting ability of these fungi.
\end{abstract}

Keywords: Control, keratinophilic fungi, keratin and Growth behaviour.

\section{Introduction}

keratinophilic fungi are a group of fungi based on their occurrence and association with the specific substrates containing complex nitrogenous material, the keratin , widely occurring with hair, feather, nail, hoof, horn and skin. This group of fungi cause destruction of hair, wool and woollen garments (Bonar and Dreyer1932, Williams J.W.1934a,1935, Hirschmaan et al 1944,Sur and Ghosh1980).

The wide occurrence of these fungi on the keratinous substrata compel to realise their nutritional behaviour related with their enzymes released extracellularly to dissolve the polymeric keratin but surprisingly enough, they were reported to be incapable of digesting .

\section{Materials And Methods}

During investigation altogether 19different fungal species were isolated from feathers of 12different birds, hair of 5 different animals and human nails using bait technique method. All fungal isolates were grown on Sabouraud Dextrose Agar using composition as follows-

$\begin{array}{ll}\text { Neopeptone - } & 10 \mathrm{gm} . \\ \text { Dextrose- } & 40 \mathrm{gm} . \\ \text { Agar- } & 15 \mathrm{gm} . \\ \text { Distilled water- } & 1000 \mathrm{ml} .\end{array}$

Now to see the influence of keratin on the growth of these keratinophilic fungal isolates peptone was replaced by $1 / 10^{\text {th }}$ of its weight of Keratin in S.D. liquid medium (without Agar).

These nineteen fungal species were grown on a thin layer of Sabaraude Dextrose Agar Medium in petridishes at $25^{\circ} \mathrm{c}$ and $\mathrm{pH}$ 7. After incubation period of 10 days, $5 \mathrm{~m} . \mathrm{m}$. blocks were cut and transferred aseptically to $250 \mathrm{~m} .1$. conical flasks containing sterilized $50 \mathrm{~m} .1$. liquid S.D. medium in which peptone was replaced by $1 / 10^{\text {th }}$ of its weight of Keratin. PH of the medium was adjusted to 7 and incubated for 15 days in BOD incubator. After the incubation period, the mycelia mats were collected by filtering them through preweighed Whitman's 1 to 1 filter paper individually and it was transferred to labelled butter paper envelope. It was dried inside an incubator at temperature of $60 \pm 1^{\circ} \mathrm{C}$. After 24 hours of this drying procedure the envelops with mycelial mats were kept in a sealed desiccators over fused calcium chloride for 24 hours. The actual weight of fungal mycelium was then calculated using the formula-

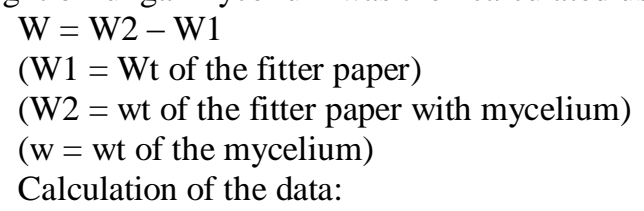

The available data of mean dry weight of mycelium was calculated along with standard error (S.E.). The data were further analyzed statistically for A nova and C.D recorded.

\section{Results And Conclusions}

It seems (Table-1and Graph-1\&2) that the effect of keratin differs significantly from the control in case of all the species and further the growth of different species differs significantly from each other except the noted here. 
Table- 1

Influence of keratin on the growth of some keratinophilic fungi isolated from different sources (PH 5.8, Temp $25 \pm 1^{\circ} \mathrm{C}$ )

[Expressed as mean dry weight in mg.]

\begin{tabular}{|l|l|l|}
\hline Fungus species & Growth on keratin & Control \\
\hline Aspergillus caespitosus & $171.000 \pm 2.082$ & $74.333 \pm 2.333$ \\
\hline Aspergillus candidus & $175.000 \pm 2.887$ & $39.000 \pm 2.082$ \\
\hline Aspergillus flavus & $135.666 \pm 2.333$ & $42.333 \pm 1.453$ \\
\hline Aspergillus nidulans & $117.666 \pm 1.453$ & $37.666 \pm 1.453$ \\
\hline Aspergillus oryzae & $195.000 \pm 2.887$ & $40.000 \pm 2.887$ \\
\hline Aspergillus terreus & $125.666 \pm 2.963$ & $70.000 \pm 1.155$ \\
\hline Chaetomium globosum & $140.000 \pm 2.887$ & $79.333 \pm 1.764$ \\
\hline Chaetomium homopilatum & $129.000 \pm 2.082$ & $56.666 \pm 1.666$ \\
\hline Chaetomium bostrichodes & $202.666 \pm 1.453$ & $40.000 \pm 1.155$ \\
\hline Curvularia lunata & $432.333 \pm 1.453$ & $117.666 \pm 1.453$ \\
\hline Gleomastix murorum & $89.000 \pm 2.082$ & $59.000 \pm 2.082$ \\
\hline Histoplasma capsulatum & $216.666 \pm 1.666$ & $57.666 \pm 1.453$ \\
\hline Monosporium apiospermum & $182.666 \pm 1.762$ & $27.666 \pm 1.453$ \\
\hline Microsporum canis & $345.000 \pm 2.887$ & $215.666 \pm 0.666$ \\
\hline Rhizopus oryzae & $115.666 \pm 2.333$ & $22.333 \pm 1.453$ \\
\hline Torula graminis & $285.000 \pm 2.887$ & $39.000 \pm 0.577$ \\
\hline Trichoderma lignorum & $195.000 \pm 2.887$ & $31.000 \pm 2.082$ \\
\hline Trichophyton viride & $284.333 \pm 2.333$ & $35.000 \pm 2.887$ \\
\hline Trichophyton verrucosum & $440.000 \pm 2.887$ & $38.333 \pm 0.882$ \\
\hline
\end{tabular}

Graphs showing Influence of keratin on the growth of some keratinophilic fungi (pH 7, temp 25+0.5 ${ }^{0 \mathrm{c}}$ ) (Expressed as mean dry weight in $\mathrm{mg}$ )

Graph 1

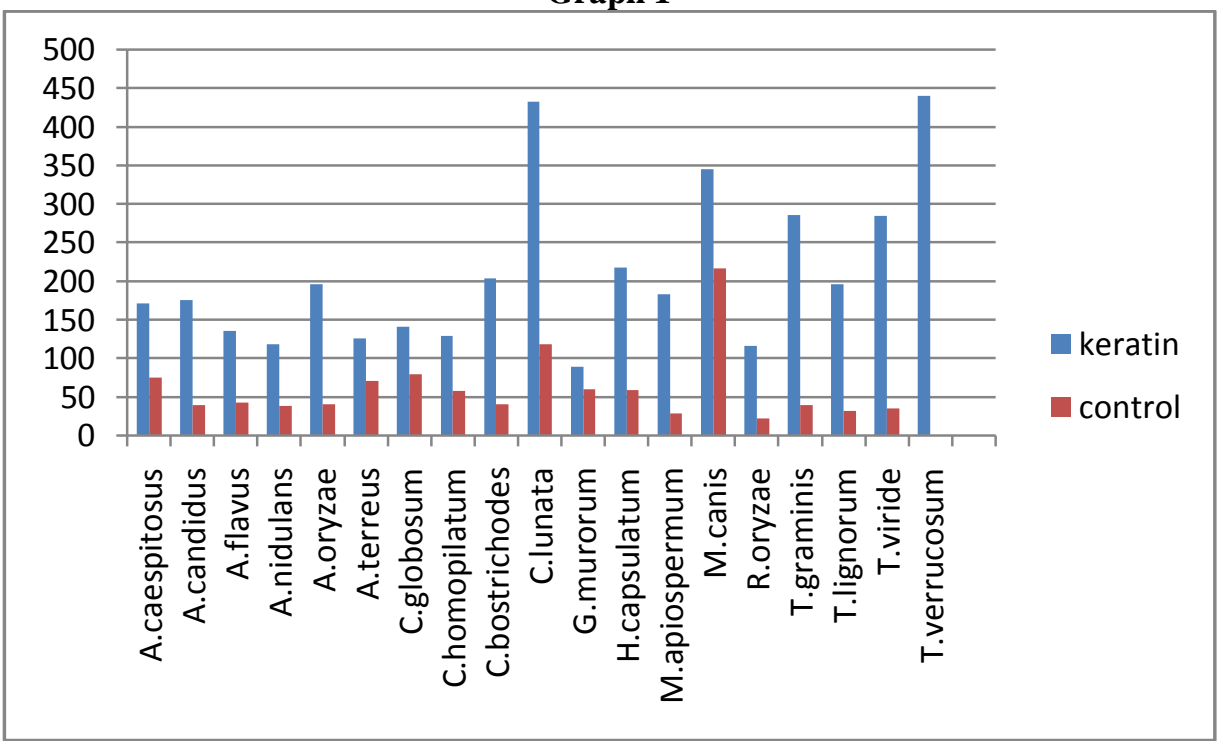

Graph 2 


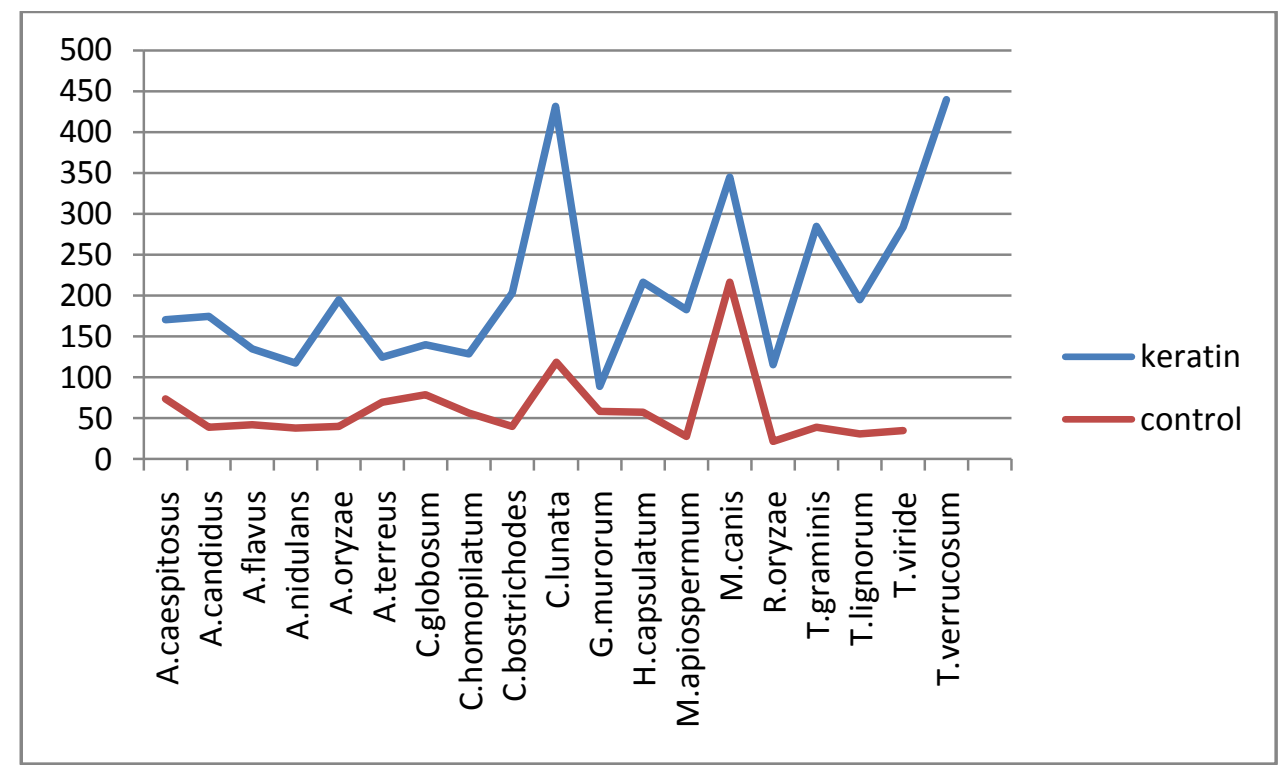

Trichophyton verrucosum provided maximum amount of mycelium while Gleomastix murorum the minimum in amount. The mean dry weight produced by the different isolates can be arranged in descending order as follows-

Trichophyton verrucosum > Curvularia lunata> Microsporum canis> Trichophyton viride> Torula graminis> Histoplasma capsulatum > Chaetomium bostrichodes >Trichoderma lignorum> Aspergillus oryzae >Monosporium apiospermum > Aspergillus candidus > Aspergillus caespitous > Chaetomium globosum > Aspergillus flavus > Chaetomium homopilatum > Aspergillus terreus $>$ Aspergillus nidulans > Rhizopus oryzae > Gleomastix murorum.

The considerable growth of these isolates on keratin like polymer is not at all possible without the hydrolysis to simpler fractions. The present finding corroborates the keratin digesting ability which was also observed after hydrolysis of hair (Page1950, Chesters and Mathison 1965).As they were reported to grow on almost all keratin containing substances, impact of presence of keratin also showed more influence on their growth in comparison to control. Trichophyton verrucosum, Microsporum canis, Trichophyton viride and Monosporium apiospermum were already reported to cause so many skin diseases in man and other animals also. Their luxuriant growth on keratin also showed their dermophytic behaviour and causing skin diseases to susceptible one.

\section{Discussion}

El-Naghy, M.A., et al, (1998) reported degradation of chicken feathers by Chrysosporiumgeorgiae, while Deshmukh, S.K., Agrawal, S.C., (1985)found degradation of human hair by some dermatophytes and other keratinophilic fungi. Filipello Marchisio V et al(1994,2000) reported that keratinolytic fungi are dermatophytes and their correlates, especially Microsporum, Trichophyton, Aphanoascus, Chrysosporium, Geomyces, Gymnoascus, Malbranchea and Myceliophthora species. These fungi played an important ecological role in decomposing keratins, the insoluble fibrous proteins. .Krystyna et al (1991) shows the keratinolytic activity of dermatophytes in vitro. Williams J.W. (1934a, 1935) used scalp products and hair as a culture medium fto grow certain pathogenic fungi. El-Naghy, M.A., et al,(1998) and Sanjana Kaul and Geeta Sumbali (1999) identifierd theProduction of extracellular keratinases by keratinophilic fungal sps inhabiting feathers of living poultry birds. Bonar,L. and Dreyer A.D.(1932) studied on ringworm fungus with reference to public health problems.

\section{References}

[1]. Bonar,L. and Dreyer A.D.(1932). "Studies on ringworm fungus with reference to public health problems" Amer. Jour. Publ. Health. 22:909-926.

[2]. Deshmukh, S.K., Agrawal, S.C., (1985). "Degradation of human hair by some dermatophytes and other keratinophilic fungi."Mykosen, 28: 463-466.

[3]. El-Naghy, M.A., et al,(1998). "Degradation of chicken feathers by Chrysosporiumgeorgiae."Mycopathologia, 143: 77-84.

[4]. Fillipello, M.V., et al ., (1994) " Keratinolysis and its morphological expression in hair digestion by airborne fungi."Mycopathologia, 127:103-115.

[5]. Fillipello, M.V., et al., (eds.), (2000). "Keratinophilic fungi: their role in nature anddegradation of keratinic substrates. Biology of dermatophytes and other keratinoplilic fungi."RevistaIberoamericana de Micologia, Spain, pp 77-85.

[6]. Hirschmaan, D.J., M. Zametkinand R.E.Rogers( 1944). "The utilization of wool by four saprophytic microorganisms in the presence of additional nutrients." Amer. Dyest. Rep.33:353-359. 
[7]. Krystyna et al (1991)“ Screening the keratinolytic activity of dermatophytes in vitro.” Mycopathologia, 114: 1-8.

[8]. Williams J.W. (1934a). "Scalp products and hair as a culture medium for certain pathogenic fungi."Proc. Soc.Exp.Biol.and Med.31:944-945.

[9]. Williams J.W.(1935). "Scalp products and hair of men and women as culture media for certain pathogenic fungi." Proc. Soc.Exp.Biol.and Med.32:624-625.

[10]. Sanjana Kaul and Geeta Sumbali (1999) "Production of extracellular keratinases by keratinophilic fungal sps inhabiting feathers of living poultry birds(Gallus domesticus)a comparision" Mycopathologia, 146: 19-24.

[11]. Sur,B. and G.R. Ghosh (1999) "Keratinophilic fungi from Orissa,India.II. Isolation from feathers of wild birds and domestic fowls". Sabouradia, 18:275-280. 